\title{
CHARACTERISTICS AND DEVELOPMENT OF NONSUICIDAL SUPER SELF-INJURY AMONG BORDERLINE INPATIENTS
}

\author{
Katalin Merza ${ }^{1}$, Gábor Papp ${ }^{2}$, Judit Molnár ${ }^{1}$ \& Ildikó Kuritárné Szabó ${ }^{1}$ \\ ${ }^{I}$ University of Debrecen, Faculty of Public Health, Institute of Behavioral Sciences, Debrecen, Hungary \\ ${ }^{2}$ University of Debrecen, Institute of Psychology, Debrecen, Hungary
}

received: 23.12.2016;

revised: 19.4.2017;

accepted: 1.6 .2017

\begin{abstract}
SUMMARY
Background: Nonsuicidal self-injury (NSSI) is a key feature of borderline personality disorder (BPD), which is strongly associated with childhood traumatization. To the best of our knowledge, there has been a lack of studies investigating extensively the characteristics of borderline patients who engage in extremely high numbers of NSSI, and their features of NSSI, trauma history and psychopathology. The aim of this study is to identify groups of borderline inpatients on the basis of the lifetime number of NSSI, and to explore the characteristics of these groups regarding the onset, reasons and methods of NSSI, history of childhood traumatization, and severity of psychopathology.

Subjects and methods: 80 psychiatric inpatients with BPD were included in the study, of whom 63 had a history of NSSI and 17 had not. The frequency and characteristics of NSSI were assessed by the Ottawa Self-Injury Inventory and the childhood traumatization were assessed by the Traumatic Antecedents Questionnaire and the Early Trauma Inventory.

Results: In this study among self-injuring borderline inpatients a super self-injuring group was identified, who engaged in extremely high numbers of NSSI (75.0 28.4 acts/lifetime). Compared to moderate self-injurers, super self-injurers began harming themselves at a younger age ( $p=0.008)$, used more severe forms of NSSI, and all of them reported an anti-dissociation function of NSSI. Adverse childhood experiences were more prevalent in the super self-injuring group. The strongest predictors of the lifetime number of NSSI were early sexual abuse $(p<0.001)$, intrafamilial physical abuse $(p<0.001)$, a higher cumulative trauma score $(p=0.030)$ and a greater number of BPD criteria $(p<0.001)$.

Conclusions: Our results suggest that the frequency of NSSI in borderline inpatients can be seen as an indicator of clinicallyrelevant anamnestic data, namely, of the severity, complexity and onset of childhood traumatization, and of the severity of current borderline psychopathology.
\end{abstract}

Key words: borderline personality disorder (BPD) - nonsuicidal self-injury - childhood traumatization - sexual abuse

\section{INTRODUCTION}

Nonsuicidal self-injury (NSSI) is a type of selfinjurious behavior, refers to the self-inflicted, direct, socially unacceptable destruction or alteration of body tissue without a conscious suicidal intent (Nock et al. 2006, Yates 2004). NSSI is often a key feature of borderline personality disorder (BPD) (Dubo et al. 1997) and is sometimes referred to as the borderline patient's "behavioral specialty" (Sansone 2004). Though NSSI has historically been conceptualized as a feature of BPD, it can occur among adolescents without BPD (Csorba et al. 2010, Swannel et al. 2014), and in a wide range of other mental disorders (Sansone et al. 2007), including substance-dependency (Evren et al. 2006), psychotic disorders (Martin \& Gattaz 1991); eating disorders (Paul et al. 2002, Sansone \& Levitt 2002), and post-traumatic stress disorder (Zlotnick et al. 1999). Although NSSI is frequently associated with different psychiatric diagnoses and it has long been regarded as a pathognomonic of BPD, DSM-5 proposes non-suicidal self-injury as a separate diagnostic entity (American Psychiatric Association 2013).

In borderline samples the lifetime prevalence of NSSI is $57-75 \%$ (Fyer 1988, Gunderson 1984, Linehan
1993), and $80 \%$ among borderline inpatients with more severe psychopathology (Shearer et al. 1988). Dubo et al. (1997) identified a subgroup of borderline inpatients engaged in extremely high numbers of NSSI. In his study $40.5 \%$ of patients had made 50 or more nonsuicidal self-injurious efforts in their lifetime, and some patients reported more than a hundred NSSI. NSSI is more common in females than in males (Favazza 1999), and it tends to begin in childhood (before the age of 12) or adolescence (between the ages of 13-17 years) (Zanarini et al. 2006). Patients who start NSSI at a very young age report more episodes and a longer duration of self-injury, continuing into adulthood (Dubo et al. 1997, Zanarini et al. 2006); however, the prevalence of episodes of NSSI declines significantly over the lifetime (Sansone \& Wiederman 2014, Zanarini et al. 2008, Zanarini et al. 2013). The most frequent methods of NSSI reported by borderline patients are cutting, hitting self/object and burning (Briere \& Gil 1998, Nijman et al. 1999, Shearer 1994). Patients who report more NSSI engage in more severe forms of this behavior, such as head-banging or bone-breaking (Nixon et al. 2002).

There is a growing body of evidence suggesting that complex childhood traumatization has a role in the etiology of BPD (Bandelow et al. 2005, Merza et al. 2015, 
Sabo 1997, Wingenfeld et al. 2011, Zanarini 2000). Studies have found that histories of adverse childhood experiences, including physical abuse, sexual abuse, neglect and separation are strongly associated with NSSI (Brodsky et al. 1997, Silk et al. 1997, van der Kolk et al. 1991, Zanarini et al. 2002). Furthermore, childhood sexual abuse and its parameters, such as early onset and incest are strongly associated with NSSI (Matsumoto et al. 2004, Romans et al. 1995, Westen et al. 1990, Zanarini et al. 2011, Zweig-Frank \& Paris 1997).

The association of childhood abuse history with NSSI may be mediated by a causal relationship between childhood abuse experiences and the development of affect dysregulation, which might then be associated with NSSI in adulthood (Brodsky et al. 1997, Stanley \& Brodsky 2005). NSSI can be considered as an attempt to gain a sense of control over oneself during high arousal states (Klonsky 2007, 2009; van der Kolk et al. 1991). More specifically, it can express, validate and regulate intolerable and overwhelming emotional states, such as dysphoric feelings, tension, emotional pain, distress, or anger (Nixon et al. 2002, Paivio 2004, Suyemoto 1998, Zanarini et al. 2013). NSSI can also help borderline patients control unpleasant self-states, and provide relief from dissociation and depersonalization (Brodsky et al. 1995, Nixon et al 2002, Zanarini et al. 2013). Zanarini et al. (2013) found that patients with a more extensive history of NSSI reported internally-directed reasons for self-injury, for example, to relieve anxiety, lessen emotional pain, stop feeling numb and punish self. NSSI is often accompanied by analgesia, perhaps suggesting the release of endogenous opiates during acute intensification of dysphoric states (Bunderla \& Kumperscak, 2015, Russ et al. 1993).

Though the intention of NSSI is non-lethal, it can have serious consequences (e.g. life-threatening injuries or accidental death), furthermore, there is a strong association between NSSI and suicide attempts (Dubo et al. 1997, Glenn \& Klonsky 2009). Therefore, the assessment of possible NSSI is important in the assessment of individuals with BPD diagnosis, with a view to managing and reducing risk. However, the risk of NSSI is often underestimated (Stanley \& Brodsky 2005).

To the best of our knowledge, there has been a lack of studies investigating extensively the characteristics of borderline patients who engage in extremely high numbers of NSSI, and their features of NSSI, trauma history and psychopathology.

The aim of this study is to identify groups of borderline inpatients who engage in different amounts of nonsuicidal self-injury, and explore the characteristics of these groups regarding the onset, reasons and methods of NSSI, the history of childhood traumatization, and the severity of psychopathology.

In this study a non-injuring borderline group was chosen to reveal the probable differences between the self-injuring and non-injuring groups for the trauma histories and for the severity of borderline psychopathology.

\section{SUBJECTS AND METHODS}

A brief methodology will be presented in this article, because it has been described in detail elsewhere (Merza et al. 2015). The study followed the ethics declaration of Helsinki and prior to data collection the project was approved by the Hungarian Scientific and Medical Ethics Committee (ETT-TUKEB, No. 3344/2012/EKU).

\section{Subjects}

Ninety-two inpatients were recruited from eight Hungarian public psychiatric hospitals. All patients were initially screened to determine that they 1) were between the ages of 18 and 50 years; 2) had at least an average level of intellectual functioning and 3) had been given a definite or a probable clinical diagnosis of BPD by a senior psychiatrist. Patients with current symptoms or a history of 1) bipolar mood disorder 2) major psychotic disorder or 3) cognitive impairment were excluded. After providing patients with a complete description of the study, written informed consent was obtained from each of them. The Hungarian version of Structured Clinical Interview for DSM-IV Axis I and Axis II disorders (SCID-I-II) (Szádóczky et al. 2004, 2006) was then administered to confirm the diagnosis of BPD and to assess comorbid disorders. Twelve of ninety-two participants were eliminated by the diagnostic interview: eight because they were found to have disorders excluded from this study, as above, and four, because they met less than five BPD diagnostic criteria.

The interviews were conducted by the first author, a highly trained psychologist.

\section{Methods}

Nonsuicidal self-injury was assessed by the Hungarian clinical version of Ottawa Self-Injury Inventory (OSI) (Csorba et al. 2005). OSI is a self-reporting measure which gathers information about the onset, frequency, severity, reasons and methods of NSSI and the frequency of suicide attempts.

Experiences of childhood traumatization were assessed by the Traumatic Antecedents Questionnaire (TAQ) (van der Kolk \& Smyth 2010). The TAQ is a 42-item self-report questionnaire for gathering information about the frequency and severity of traumatic and adaptive experiences and it has been used by many researchers (McLean \& Gallop 2003, Saxe et al. 1993). In this study only 6 subscales of the TAQ were used, selected for the purpose of assessing traumatic or adverse experiences. These subscales cover neglect, separation, emotional abuse and physical abuse by a caretaker or family member, sexual abuse by an adult and witnessing of domestic violence. These adverse experiences were assessed at four different developmental periods: early childhood (0-6 years), latency (712 years), adolescence (13-18 years), and adulthood (over 18 years). In addition to the TAQ, the Sexual Abuse subscale of the Early Trauma Inventory (ETI) 
(Bremner et al. 2007) was used to assess childhood experiences of sexual abuse in more detail. This 15 -item scale gathers information about frequency, age at onset, use of force, relationship to the perpetrator and nature of sexual abuse at four developmental stages (similar to the developmental stages of the TAQ).

\section{Statistical Analyses}

Two-step cluster analysis was carried out to discriminate the patients on the basis of the number of NSSI into groups. This method enables data with both continuous and categorical data to be clustered and it determines the ideal number of clusters. The analysis was based on one categorical variable (whether the patient reported any NSSI or not) and one continuous variable (the number of NSSI). Between-group comparison of age, involving continuous data were computed by means of one-way analysis of variance. Chi-square tests were performed to compare the frequency distributions of certain demographic characteristics, the methods and reasons of NSSI, traumatic experiences, and the nature of sexual abuse among the groups. When cell sizes were five or less, Fischer's exact test of probability was used. For quantitative variables (certain characteristics of NSSI, severity of psychopathology and cumulative trauma score) group differences were tested using Kruskal-Wallis and Mann-Whitney U tests.

Multiple regression analysis was used to test the research question regarding the possible predictors of NSSI. A p value less than 0.05 was considered statistically significant. The statistical analyses were performed by the SPSS statistical package version 20.0.

\section{RESULTS}

The sample consisted of 80 psychiatric inpatients with the diagnosis of BPD, of whom 63 patients (78.8\%) had a history of NSSI and 17 patients $(22.2 \%)$ did not report NSSI. To examine whether the number of NSSI could be used to distinguish groups of selfinjurers, a two-step cluster analysis was carried out. Among self-injurers two groups were identified; in the first group $(n=44)$ the mean number of lifetime instances of NSSI was $11.2( \pm 9.1)$, and in the second group $(\mathrm{n}=19)$ this number was $75.0( \pm 28.4)$. The second group of patients, engaged in extremely high numbers of NSSI, were defined as "super self-injurers", based on Dubo et al. (1997).

The analyses below pertain to three groups of the borderline sample, the non-injuring patients, the moderate self-injuring patients and the super selfinjuring patients. Table 1 presents the comparison of demographic data for the groups. To evaluate age differences among the groups one-way analysis of variance (ANOVA) was conducted. ANOVA did not reveal significant differences among the groups $(\mathrm{F}=1.061, \mathrm{p}=0.351)$, the mean ages were $33.9( \pm 9.99)$ years for the non-injuring group, $29.6( \pm 10.76)$ years for the moderate self-injuring group and $29.7( \pm 11.82)$ for the super self-injuring group. Chi-square test for the categorical data showed significant differences in employment $\left(\chi^{2}=22.82, p=0.029\right)$ among the groups, with super self-injurers more likely to be unemployed than moderate self-injurers and non-injurers. The groups were found to be similar in sex distribution $\left(\chi^{2}=2.411\right.$, $\mathrm{p}=0.299$ ), with all groups containing more females than males. There were no statistically significant differences between the groups for marital status $\left(\chi^{2}=10.96\right.$, $\mathrm{p}=0.204)$ or educational level $\left(\chi^{2}=7.62, \mathrm{p}=0.107\right)$.

\section{Characteristics of nonsuicidal self-injury}

The analyses of the characteristics of NSSI implicitly pertain to the two self-injuring groups in the sample, the moderate self-injuring patients and the super self-injuring patients.

In terms of age at onset of NSSI, we found significant differences $(\mathrm{U}=241.0, \mathrm{p}=0.008)$ between the two self-injuring groups: those in the super self-injuring group began harming themselves at a mean age of 13.9 $( \pm 3.8) \quad(M d n=14)$ years, while those in the moderate group had began harming themselves at a mean age of $17.8( \pm 6.6)(\mathrm{Mdn}=16)$ years. Table 2 lists the methods of NSSI reported by the two groups. In both groups the three most common methods of NSSI were cutting, scratching and self-hitting. The groups did not differ significantly on the prevalence of the following types of NSSI: cutting $\left(\chi^{2}=2.646, p=0.104\right)$, scratching $\left(\chi^{2}=2.510\right.$, $\mathrm{p}=0.113)$, self-hitting $\left(\chi^{2}=3.621, \mathrm{p}=0.057\right)$, skin-biting $\left(\chi^{2}=3.755, \mathrm{p}=0.053\right)$, head-banging $\left(\chi^{2}=3.064, \mathrm{p}=0.080\right)$, and nail-biting $\left(\chi^{2}=1.378, \mathrm{p}=0.240\right)$. In contrast, we found that significantly more super self-injurers than moderate self-injurers used burning $\left(\chi^{2}=5.368\right.$, $\mathrm{p}=0.021)$, hair pulling $\left(\chi^{2}=8.585, \mathrm{p}=0.003\right)$ and needles $\left(\chi^{2}=4.363, p=0.037\right)$.

Reported number of lifetime instances of emergency treatments following an episode of NSSI was significantly different between the groups $(U=228.5, p<0.001)$. Mean number of instances when the individuals have been referred to an emergency room was $3.47( \pm 5.27)$ $(\mathrm{Mdn}=0)$ among super self-injurers, and $1.09( \pm 4.25)$ $(\mathrm{Mdn}=1)$ among moderate self-injurers.

We also examined the most common reasons given for engaging in NSSI. Table 3 shows that among super self-injurers the top three reasons given for NSSI were 'stop feeling numb', 'cope with nervousness' and 'release unbearable tension'. The first two reasons were reported by each of the super self-injurers. In the moderate self-injuring group the three most common reasons were 'release unbearable tension', 'cope with nervousness' and 'express anger'. Chi-square tests indicated significant differences between the moderate selfinjuring and super self-injuring groups for 'express anger' $\left(\chi^{2}=4.98, \mathrm{p}=0.026\right)$, 'cope with nervousness' $\left(\chi^{2}=6.40, p=0.026\right)$ and 'stop feeling numb' $\left(\chi^{2}=15.64\right.$, $\mathrm{p}<0.001)$. In the super self-injuring group these reasons were more prevalent than in the other group. 
Table 1. Demographic characteristics of the non-injuring (NI), moderate self-injuring (MSI) and super self-injuring (SSI) groups

\begin{tabular}{|c|c|c|c|c|c|}
\hline Demographic characteristic & $\begin{array}{c}\text { NI } \\
(n=17)\end{array}$ & $\begin{array}{c}\text { MSI } \\
(n=44)\end{array}$ & $\underset{(n=19)}{\text { SSI }}$ & $\chi^{2}$ & $\mathrm{p}$ \\
\hline Age (Mean, SD)* & $33.9 \pm 9.99$ & $29.6 \pm 10.76$ & $29.7 \pm 11.82$ & & 0.351 \\
\hline \multicolumn{6}{|l|}{ Sex } \\
\hline Male & $4(23.5 \%)$ & $7(15.9 \%)$ & $1(5.3 \%)$ & $2.41(\mathrm{df}=2)$ & 0.299 \\
\hline Female & $13(76.5 \%)$ & $37(81.4 \%)$ & $18(94.7 \%)$ & & \\
\hline \multicolumn{6}{|l|}{ Marital status } \\
\hline Single & $7(41.4 \%)$ & $28(63.6 \%)$ & $15(78.9 \%)$ & $10.96(\mathrm{df}=8)$ & 0.204 \\
\hline Married & $0(0.0 \%)$ & $3(6.8 \%)$ & $0(0.0 \%)$ & & \\
\hline Common-law marriage & $4(23.5 \%)$ & $6(13.6 \%)$ & $0(0.0 \%)$ & & \\
\hline Divorced & $5(29.4 \%)$ & $6(13.6 \%)$ & $3(15.8 \%)$ & & \\
\hline Relict & $1(5.9 \%)$ & $1(2.3 \%)$ & $1(2.3 \%)$ & & \\
\hline \multicolumn{6}{|l|}{ Education } \\
\hline Primary school or below & $5(29.4 \%)$ & $12(27.3 \%)$ & $2(10.5 \%)$ & $7.62(\mathrm{df}=4)$ & 0.107 \\
\hline Secondary school & $9(52.9 \%)$ & $25(56.8 \%)$ & $17(89.5 \%)$ & & \\
\hline University & $3(17.6 \%)$ & $7(15.9 \%)$ & $0(0.0 \%)$ & & \\
\hline \multicolumn{6}{|l|}{ Employment } \\
\hline Unemployed & $3(17.6 \%)$ & $16(36.4 \%)$ & $11(57.9 \%)$ & $22.82(\mathrm{df}=12)$ & 0.029 \\
\hline Disabled & $1(5.9 \%)$ & $8(18.2 \%)$ & $4(21.1 \%)$ & & \\
\hline Full-time & $3(17.6 \%)$ & $3(6.8 \%)$ & $0(0.0 \%)$ & & \\
\hline Part-time & $4(23.5 \%)$ & $2(4.5 \%)$ & $0(0.0 \%)$ & & \\
\hline Temporary & $2(11.8 \%)$ & $1(2.3 \%)$ & $1(5.3 \%)$ & & \\
\hline Student & $2(11.8 \%)$ & $12(27.3 \%)$ & $2(10.5 \%)$ & & \\
\hline Other & $2(11.8 \%)$ & $2(4.5 \%)$ & $1(5.3 \%)$ & & \\
\hline
\end{tabular}

Note: * $\mathrm{F}=1.061$

Table 2. Methods of nonsuicidal self-injury in the moderate self-injuring (MSI) and super self-injuring (SSI) groups, assessed by the OSI

\begin{tabular}{lcccc}
\hline Methods of NSSI & $\begin{array}{c}\text { MSI } \\
(\mathrm{n}=44)\end{array}$ & $\begin{array}{c}\text { SSI } \\
(\mathrm{n}=19)\end{array}$ & $\begin{array}{c}\chi^{2} \\
(\mathrm{df}=1)\end{array}$ & $\mathrm{p}$ \\
\hline Cutting & $31(70.4 \%)$ & $17(89.5 \%)$ & 2.646 & 0.104 \\
Scratching & $23(52.3 \%)$ & $14(73.7 \%)$ & 2.510 & 0.113 \\
Self-hitting & $21(47.7 \%)$ & $14(73.7 \%)$ & 3.621 & 0.057 \\
Burning & $12(27.3 \%)$ & $11(57.9 \%)$ & 5.368 & 0.021 \\
Biting (skin) & $12(27.3 \%)$ & $10(52.6 \%)$ & 3.755 & 0.053 \\
Head-banging & $11(25.0 \%)$ & $9(47.4 \%)$ & 3.064 & 0.080 \\
Hair-pulling & $9(20.5 \%)$ & $11(57.9 \%)$ & 8.585 & 0.003 \\
Nail-biting & $8(18.2 \%)$ & $6(31.6 \%)$ & 1.378 & 0.240 \\
Using needles & $6(13.6 \%)$ & $7(36.8 \%)$ & 4.363 & 0.037 \\
\hline
\end{tabular}

Table 3. Reasons for nonsuicidal self-injury (NSSI) in the moderate self-injuring (MSI) and super self-injuring (SSI) groups, assessed by the OSI

\begin{tabular}{lcccc} 
Reasons for NSSI & $\begin{array}{c}\text { MSI } \\
(\mathrm{n}=44)\end{array}$ & $\begin{array}{c}\text { SSI } \\
(\mathrm{n}=19)\end{array}$ & $\begin{array}{c}\chi^{2} \\
(\mathrm{df}=1)\end{array}$ & $\mathrm{p}$ \\
\hline Release tension & $38(86.4 \%)$ & $18(94.7 \%)$ & 0.94 & 0.332 \\
Express anger & $27(61.4 \%)$ & $17(89.5 \%)$ & 4.98 & 0.026 \\
Express frustration & $24(54.5 \%)$ & $15(78.9 \%)$ & 3.35 & 0.067 \\
Cope with nervousness & $32(72.7 \%)$ & $19(100 \%)$ & 6.40 & 0.011 \\
Stop feeling numb & $21(47.7 \%)$ & $19(100 \%)$ & 15.64 & $<0.001$ \\
\hline
\end{tabular}

Table 4. Reported rates of childhood traumatization in the non-injuring (NI), moderate self-injuring (MSI) and super self-injuring (SSI) groups before the age of 18, assessed by the TAQ

\begin{tabular}{lccccc}
\hline Type of traumatization & $\begin{array}{c}\text { NI } \\
(\mathrm{n}=17)\end{array}$ & $\begin{array}{c}\text { MSI } \\
(\mathrm{n}=44)\end{array}$ & $\begin{array}{c}\text { SSI } \\
(\mathrm{n}=19)\end{array}$ & $\begin{array}{c}\chi^{2} \\
(\mathrm{df}=2)\end{array}$ & $\mathrm{p}$ \\
\hline Neglect & $13(76.5 \%)$ & $40(90.9 \%)$ & $16(84.2 \%)$ & 2.24 & 0.326 \\
Separation & $8(47.1 \%)$ & $38(86.4 \%)$ & $18(94.7 \%)$ & 15.22 & $<0.001$ \\
Emotional abuse & $13(76.5 \%)$ & $38(86.4 \%)$ & $19(100 \%)$ & 4.66 & 0.097 \\
Physical abuse & $9(52.9 \%)$ & $29(65.9 \%)$ & $14(73.7 \%)$ & 1.73 & 0.421 \\
Sexual abuse & $4(23.5 \%)$ & $26(59.1 \%)$ & $19(100 \%)$ & 22.29 & $<0.001$ \\
Witnessing & $7(41.2 \%)$ & $36(81.8 \%)$ & $19(100 \%)$ & 18.85 & $<0.001$ \\
\hline
\end{tabular}




\section{Adverse childhood experiences}

The analyses of the adverse childhood experiences pertain to the three groups in the sample, the noninjuring patients, the moderate self-injuring patients and the super self-injuring patients.

Table 4 compares the three groups (non-injurers, moderate self-injurers, super self-injurers) on overall rates of reported childhood traumatization, specifically, neglect by caretakers, separation from caretakers, intrafamilial emotional and physical abuse, intra/extrafamilial sexual abuse and witnessing family violence, assessed by the TAQ. A Chi-square test revealed significant differences among the groups for separation $\left(\chi^{2}=15.22, p<0.001\right)$, sexual abuse $\left(\chi^{2}=22.29, p<0.001\right)$ and witnessing trauma $\left(\chi^{2}=18.85, \mathrm{p}<0.001\right)$ before the age of 18 . The rates of these types of traumatization were the highest in the group of super self-injurers, and the lowest in the group of non-injurers.

Table 5 presents the prevalence of adverse experiences reported by the groups at the three developmental periods of the TAQ, early childhood (0-6 years), latency (7-12 years) and adolescence (13-18 years). A Chi-square test indicated significant differences among the groups at each developmental period for sexual abuse (Early childhood: $\chi^{2}=41.28, p<0.001$; Latency: $\chi^{2}=12.97, \mathrm{p}=0.002 ;$ Adolescence: $\chi^{2}=18.81, \mathrm{p}<0.001$ ) and witnessing trauma (Early childhood: $\chi^{2}=13.44$, $\mathrm{p}<0.001$; Latency: $\chi^{2}=10.19, \mathrm{p}=0.006$; Adolescence: $\chi^{2}=8.45, p=0.015$ ). More specifically, the reported rates of sexual abuse and witnessing trauma were the highest among the super self-injurers, as shown by the comparisons between the groups. Furthermore, we found significant differences among the groups for emotional abuse during early childhood $\left(\chi^{2}=9.71, p=0.008\right)$ and latency $\left(\chi^{2}=11.87, \mathrm{p}=0.003\right)$, and for separation during latency $\left(\chi^{2}=8.98, \mathrm{p}=0.011\right)$ and adolescence $\left(\chi^{2}=15.89\right.$, $\mathrm{p}<0.001)$. A higher percentage of super self-injurers than moderate self-injurers and non-injurers reported having experienced emotional abuse and separation during the latter developmental periods. The lowest rates of emotional abuse and separation were found in the non-injuring group.

We calculated the number of categories of childhood traumatic events (neglect, separation, emotional/physical/ sexual abuse, witnessing, assessed by the TAQ) to which a person was exposed during childhood. The groups were compared on the median numbers of cumulative trauma scores, and the Kruskal-Wallis test revealed a large, significant difference among them $\left(\chi^{2}=19.89, \mathrm{p}<0.001\right)$. More specifically, the median numbers of cumulative trauma scores were 3 in the noninjuring group, 5 in the moderate self-injuring group and the highest, 6 in the super self-injuring group.

Table 5. Reported rates of childhood traumatization in the non-injuring (NI), moderate self-injuring (MSI) and super self-injuring (SSI) groups in three developmental periods, assessed by the TAQ

\begin{tabular}{lccccc}
\hline Type of traumatization & $\begin{array}{c}\mathrm{NI} \\
(\mathrm{n}=17)\end{array}$ & $\begin{array}{c}\mathrm{MSI} \\
(\mathrm{n}=44)\end{array}$ & $\begin{array}{c}\text { SSI } \\
(\mathrm{n}=19)\end{array}$ & $\begin{array}{c}\chi^{2} \\
(\mathrm{df}=2)\end{array}$ & $\mathrm{p}$ \\
\hline Neglect & & & & & \\
$\quad$ Early childhood & $9(52.9 \%)$ & $26(59.1 \%)$ & $15(78.9 \%)$ & 3.07 & 0.215 \\
$\quad$ Latency & $10(58.8 \%)$ & $31(70.5 \%)$ & $15(78.9 \%)$ & 1.74 & 0.419 \\
$\quad$ Adolescence & $13(76.5 \%)$ & $39(88.6 \%)$ & $16(84.2 \%)$ & 1.44 & 0.488 \\
Separation & & & & & \\
$\quad$ Early childhood & $4(23.5 \%)$ & $17(38.6 \%)$ & $11(57.9 \%)$ & 4.49 & 0.106 \\
$\quad$ Latency & $6(35.3 \%)$ & $26(59.1 \%)$ & $16(84.2 \%)$ & 8.98 & 0.011 \\
$\quad$ Adolescence & $7(41.2 \%)$ & $36(81.8 \%)$ & $18(94.7 \%)$ & 15.89 & $<0.001$ \\
Emotional abuse & & & & & \\
Early childhood & $5(29.4 \%)$ & $28(63.6 \%)$ & $15(78.9 \%)$ & 9.71 & 0.008 \\
$\quad$ Latency & $7(41.2 \%)$ & $36(81.8 \%)$ & $16(84.2 \%)$ & 11.87 & 0.003 \\
$\quad$ Adolescence & $13(76.5 \%)$ & $36(81.8 \%)$ & $19(100 \%)$ & 4.67 & 0.097 \\
Physical abuse & & & & & \\
Early childhood & $4(23.5 \%)$ & $19(43.2 \%)$ & $11(57.9 \%)$ & 4.35 & 0.113 \\
$\quad$ Latency & $4(23.5 \%)$ & $23(52.3 \%)$ & $13(68.4 \%)$ & 7.44 & 0.024 \\
$\quad$ Adolescence & $9(52.9 \%)$ & $25(56.8 \%)$ & $13(68.4 \%)$ & 1.04 & 0.595 \\
Sexual abuse & & & & & \\
Early childhood & $0(0.0 \%)$ & $3(6.8 \%)$ & $14(73.7 \%)$ & 41.28 & $<0.001$ \\
$\quad$ Latency & $1(5.9 \%)$ & $15(34.1 \%)$ & $12(62.2 \%)$ & 12.97 & 0.002 \\
$\quad$ Adolescence & $3(17.6 \%)$ & $22(50.0 \%)$ & $17(89.5 \%)$ & 18.81 & $<0.001$ \\
Witnessing & & & & & \\
$\quad$ Early childhood & $4(23.5 \%)$ & $25(56.8 \%)$ & $16(84.2 \%)$ & 13.44 & $<0.001$ \\
$\quad$ Latency & $5(29.4 \%)$ & $32(72.7 \%)$ & $13(68.4 \%)$ & 10.19 & 0.006 \\
Adolescence & $7(41.2 \%)$ & $32(72.7 \%)$ & $16(84.2 \%)$ & 8.45 & 0.015 \\
\hline
\end{tabular}


Table 6. Parameters of childhood sexual abuse in the non-injuring (NI), moderate self-injuring (MSI) and super selfinjuring (SSI) groups, assessed by the ETI

\begin{tabular}{|c|c|c|c|c|c|}
\hline Parameters & $\begin{array}{c}\text { NI } \\
(n=17)\end{array}$ & $\begin{array}{c}\text { MSI } \\
(n=44)\end{array}$ & $\begin{array}{c}\text { SSI } \\
(n=19)\end{array}$ & $\begin{array}{c}\chi^{2} \\
(\mathrm{df}=2)\end{array}$ & $\mathrm{p}$ \\
\hline \multicolumn{6}{|l|}{ Perpetrator } \\
\hline Father/Male caretaker & $0(0.0 \%)$ & $6(13.6 \%)$ & $16(84.2 \%)$ & 41.34 & $<0.001$ \\
\hline Brother & $0(0.0 \%)$ & $1(2.3 \%)$ & $1(5.3 \%)$ & 1.04 & 0.594 \\
\hline Other male & $3(17.6 \%)$ & $12(27.3 \%)$ & $2(10.5 \%)$ & 2.39 & 0.303 \\
\hline Other female & $0(0.0 \%)$ & $1(2.3 \%)$ & $1(0.0 \%)$ & 1.04 & 0.594 \\
\hline Male stranger & $1(5.9 \%)$ & $7(15.9 \%)$ & $5(26.3 \%)$ & 2.76 & 0.251 \\
\hline \multicolumn{6}{|l|}{ Nature } \\
\hline Fondling & $3(17.6 \%)$ & $21(47.7 \%)$ & $19(100 \%)$ & 25.90 & $<0.001$ \\
\hline Oral sex & $2(11.8 \%)$ & $9(20.5 \%)$ & $12(63.2 \%)$ & 14.85 & $<0.001$ \\
\hline Penetration & $1(5.9 \%)$ & $14(31.8 \%)$ & $19(100 \%)$ & 37.08 & $<0.001$ \\
\hline Incomplete penetration & $3(17.6 \%)$ & $15(34.1 \%)$ & $15(78.9 \%)$ & 15.98 & $<0.001$ \\
\hline Anal penetration & $0(0.0 \%)$ & $0(0.0 \%)$ & $2(10.5 \%)$ & 6.59 & $<0.001$ \\
\hline \multicolumn{6}{|l|}{ Frequency } \\
\hline More than once a year & $3(17.6 \%)$ & $11(25.0 \%)$ & $4(21.1 \%)$ & 0.41 & 0.815 \\
\hline Monthly & $0(0.0 \%)$ & $9(20.5 \%)$ & $10(52.6 \%)$ & 14.31 & $<0.001$ \\
\hline Weekly & $0(0.0 \%)$ & $2(4.5 \%)$ & $4(21.1 \%)$ & 6.96 & 0.031 \\
\hline Daily & $1(5.9 \%)$ & $2(4.5 \%)$ & $1(5.3 \%)$ & 0.05 & 0.975 \\
\hline \multicolumn{6}{|l|}{ Age at onset } \\
\hline Early childhood - 0-6 years & $0(0.0 \%)$ & $3(6.8 \%)$ & $14(73.7 \%)$ & 41.28 & $<0.001$ \\
\hline Latency - 7-12 years & $1(5.9 \%)$ & $12(27.3 \%)$ & $5(26.3 \%)$ & 3.43 & 0.180 \\
\hline Adolescence $-13-18$ years & $3(17.6 \%)$ & $11(25.0 \%)$ & $0(0.0 \%)$ & 5.75 & 0.057 \\
\hline
\end{tabular}

Table 7. Severity indicators of borderline psychopathology in the non-injuring (NI), moderate self-injuring (MSI) and super self-injuring (SSI) groups, assessed by the SCID-I (1) and SCID-II (2)

\begin{tabular}{lcccccccccccc}
\hline Severity indicators & \multicolumn{3}{c}{$\begin{array}{c}\text { NI } \\
(\mathrm{n}=17)\end{array}$} & \multicolumn{3}{c}{$\begin{array}{c}\text { MSI } \\
(\mathrm{n}=44)\end{array}$} & & \multicolumn{3}{c}{$\begin{array}{c}\text { SSI } \\
(\mathrm{n}=19)\end{array}$} & $\begin{array}{c}\chi^{2} \\
(\mathrm{df}=2)\end{array}$ & $\begin{array}{c}\mathrm{p} \\
\end{array}$ \\
& $\mathrm{Mdn}$ & $\mathrm{M}$ & $\mathrm{SD}$ & $\mathrm{Mdn}$ & $\mathrm{M}$ & $\mathrm{SD}$ & $\mathrm{Mdn}$ & $\mathrm{M}$ & $\mathrm{SD}$ & \\
\hline DSM-IV Axis I diagnoses (1) & 2 & 2.35 & 1.66 & 3 & 3 & 1.58 & 6 & 5.89 & 1.76 & 28.70 & $<0.001$ \\
DSM-IV BPD criteria (2) & 5 & 5.47 & 0.72 & 6 & 6.45 & 1.11 & 8 & 8 & 0.82 & 35.46 & $<0.001$ \\
DSM-IV Axis II diagnoses (2) & 1 & 1.24 & 1.20 & 1 & 1.21 & 0.90 & 3 & 2.32 & 1.00 & 14.41 & $<0.001$ \\
Age at first psychiatric treatment & 28 & 29.30 & 9.43 & 19 & 22.10 & 10.10 & 18 & 20.1 & 9.49 & 52.96 & $<0.001$ \\
Hospitalizations & 3 & 6.53 & 9.08 & 2 & 4.14 & 4.17 & 3 & 8.84 & 11.33 & 2.22 & 0.329 \\
\hline
\end{tabular}

Table 8. Significant predictors of the frequency and onset of nonsuicidal self-injury, assessed by the SCID-II (1), the TAQ (2) and the ETI (3)

\begin{tabular}{llcccc}
\hline Outcome variable & Independent variable & B & SE B & $\beta$ & $\mathrm{p}$ \\
\hline Number of acts & Number of BPD criteria (1) & 10.950 & 1.865 & 0.434 & $<0.001$ \\
& Cumulative trauma score (2) & -5.778 & 2.597 & -0.207 & 0.030 \\
& Physical abuse before the age of 12 (2) & -3.523 & 0.994 & -0.314 & $<0.001$ \\
& Sexual abuse before the age of 6 (2) & 53.378 & 6.213 & 0.672 & $<0.001$ \\
& Male perpetrator familiar to the patient (3) & -14.771 & 5.339 & -0.186 & 0.007 \\
Age at onset & Cumulative trauma score (2) & -2.380 & 0.670 & -0.407 & $<0.001$ \\
\hline
\end{tabular}

Table 6 compares non-injurers, moderate selfinjurers and super self-injurers who reported childhood sexual abuse with respect to the parameters of sexual abuse, which was assessed by the ETI. Twenty-three percent of non-injurers, 59\% of moderate self-injurers and $100 \%$ of super self-injurers reported having experienced sexual abuse before the age of 18. For patients who had been abused by more than one perpetrator, data were entered for the specific perpetrator whose abuse would be expected to be more traumatic, according to the Paris \& Zweig-Frank's
(1997) hierarchy. A significantly higher percentage of super self-injurers than moderate self-injurers and noninjurers reported childhood sexual abuse perpetrated by a father/male caretaker $\left(\chi^{2}=41.34, \mathrm{p}<0.001\right)$. There was a large, significant difference between the groups with respect to the nature of childhood sexual abuse. The prevalence of fondling $\left(\chi^{2}=25.90, \mathrm{p}<0.001\right)$, oral sex $\left(\chi^{2}=14.85, \mathrm{p}<0.001\right)$, penetration $\left(\chi^{2}=37.08, \mathrm{p}<0.001\right)$, incomplete penetration $\left(\chi^{2}=15.98, \mathrm{p}<0.001\right)$, anal sex $\left(\chi^{2}=6.59, \mathrm{p}=0.037\right)$ was higher among the super selfinjurers than among the moderate self-injurers and non- 
injurers. The prevalence of monthly regular sexual abuse was significantly higher among the super selfinjurers than among the moderate self-injurers and noninjurers before the age of $18\left(\chi^{2}=14.31, p=0.001\right)$. Moreover, a significantly higher percentage of super self-injurers experienced weekly $\left(\chi^{2}=6.96, p=0.031\right)$ regular sexual abuse. Statistical analysis revealed a significant difference between the groups for the age of the first sexual abuse event, with a significantly higher percentage of super self-injurers reporting onset before the age of $6\left(\chi^{2}=41.28, p<0.001\right)$.

\section{Severity of borderline psychopathology}

We aimed to assess the severity of borderline psychopathology in the three groups. The indicators of severity chosen follow the severity variables identified in Bateman \& Fonagy's (2013) study, including the severity of comorbid psychiatric syndromes (number of comorbid DSM-IV Axis I diagnoses), the number of DSM-IV BPD criteria, and the severity of personality disturbance (number of comorbid DSM-IV Axis II diagnoses). In addition, the number of psychiatric hospitalizations and the onset of psychiatric treatment were assessed. Table 7 shows the comparisons of the groups according to the indicators of the severity of BPD. The Kruskal-Wallis test indicated significant differences among the groups for the three severity variables identified by Bateman $\&$ Fonagy (2013): the median numbers of DSM-IV Axis I diagnosis $\left(\chi^{2}=28.70, \mathrm{p}<0.001\right)$, DSM-IV BPD criteria $\left(\chi^{2}=35.46, \mathrm{p}<0.001\right)$, and DSM-IV Axis II diagnosis $\left(\chi^{2}=14.41, p<0.001\right)$ were higher in the super selfinjuring group than in the moderate self-injuring and non-injuring groups. Furthermore, the onset of the first psychiatric treatment was significantly earlier among super self-injurers $\left(\chi^{2}=52.96, \mathrm{p}<0.001\right)$. The groups did not differ significantly on the numbers of psychiatric hospitalizations $\left(\chi^{2}=2.22, \mathrm{p}=0.329\right)$.

\section{Predictors of nonsuicidal self-injury}

Multiple regression analysis was carried out to determine the strongest predictors of the frequency and age at onset of NSSI. The dependent variables were the number of NSSI and the age at onset of NSSI. The independent variables were the types of childhood traumatization (neglect, separation, emotional abuse, physical abuse, sexual abuse, witnessing trauma), the parameters of sexual abuse (nature, perpetrator, frequency, age at onset), the cumulative trauma scores, and the severity indicators of borderline psychopathology (number of comorbid DSM-IV Axis I-II disorders, number of BPD criteria). As seen in Table 8, the lifetime number of NSSI was significantly related to physical abuse before the age of 12 , sexual abuse before the age of 6 , childhood sexual abuse perpetrated by a male who was familiar to the patient, higher cumulative trauma score, and the number of BPD criteria. Furthermore, the age at onset of NSSI was significantly related to higher cumulative trauma scores.

\section{DISCUSSION}

In this study we aimed to identify groups of borderline inpatients who engage in different amounts of nonsuicidal self-injury, and explore the characteristics of these groups regarding the onset, reasons and methods of NSSI, the history of childhood traumatization, and the severity of psychopathology.

Seven major findings emerged from this study. First, we identified a subgroup of borderline patients engaged in extremely high numbers of NSSI, called super selfinjurers. This group consisted of $23 \%$ of the sample, with a $75 \pm 28$ mean number of NSSI. Our results are consistent with those of Dubo (1997) who found a super self-injuring subgroup with more than 50 lifetime instances of NSSI.

Second, the results of our study show that the group of super self-injurers began to self-injure at a very young age. While the onset of NSSI among moderate self-injurers most commonly occurred in late adolescence (18 years), among the super self-injurers it occurred 4 years earlier, in early adolescence (14 years). The most common methods of NSSI in both groups were cutting, scratching and self-hitting which is consistent with the findings of previous studies (Shearer 1994, Briere \& Gil 1998, Nijman et al. 1999). In addition to the most common methods, a wide range of NSSI were reported by both groups (burning, biting, head-banging, hair-pulling, nail-biting, using needles).

Third, in both groups the primary reasons given for NSSI were 'cope with nervousness' and 'release unbearable tension'. This supports the hypothesis that NSSI is maladaptive attempt at affect regulation (Klonsky 2009, Zanarini et al. 2013). All the super self-injurers and half of the moderate self-injurers also reported that NSSI helps to "stop feeling numb", supporting the hypothesis that NSSI may be used to stop dissociation (Nixon et al. 2002, Zanarini et al. 2013). This result suggests that dissociative tendencies are more prevalent in the super self-injuring group.

Fourth, adverse childhood experiences, including sexual abuse and witnessing domestic violence, were more prevalent among super self-injurers than among moderate self-injurers and non-injurers in all three developmental periods. Furthermore, the higher cumulative trauma score in the super self-injuring group shows that they seemed to come from multi-abusive family environments.

Fifth, super self-injurers reported experiences of the most severe forms of sexual abuse, characterized by incest, penetration and repetitive abuse. More specifically, they reported more incest (89.5\%), weekly, regular abuse $(21.1 \%)$, abuse before the age of $6(73.7 \%)$ and more penetration (100\%) than moderate selfinjurers and non-injurers.

These findings are consistent with the findings of previous studies suggesting that the history of childhood sexual abuse and its parameters have a specific relationship to NSSI (Romans et al. 1995, Zanarini et al. 2011). 
Sixth, borderline psychopathology was more severe in the super self-injuring group than in the moderate self-injuring and non-injuring groups. More specifically, super self-injurers met more BPD criteria, and had nearly double the DSM-IV Axis I and Axis II disorders of the other two groups. This result is consistent with the finding of a previous study (Golier et al. 2003), which suggests that the mean number of the comorbid personality disorders is 2.3 among BPD patients. Furthermore, the onset of the first psychiatric treatment was earlier among super self-injurers and the number of lifetime instances of emergency treatments following an episode of NSSI was three times higher than in the other two groups.

Lastly, we have found that childhood traumatization, particularly early sexual abuse and the higher cumulative trauma score, were highly predictive of the number of NSSI, furthermore the higher cumulative trauma score was highly predictive of the early onset of NSSI. These findings are consistent with the findings of earlier studies, suggesting that sexual abuse and its parameters are important etiological factors in the development of NSSI among borderline inpatients, and that exposure to multiple traumas, particularly in early childhood, can lead to severe pathology (Matsumoto et al. 2004, van der Kolk et al. 1991, Zanarini et al. 2011).

There are several limitations of this study. First, the BPD patients in this study were more severely disturbed inpatients with a history of childhood physical and/or sexual abuse; therefore, these findings may not be generalizable to outpatients who have more moderate to milder forms of BPD. It would be potentially useful to conduct a similar study of outpatients with BPD, with the specific aim of finding out if similar groups can be distinguished in relation to NSSI. Secondly, the study is based on self-report, retrospective assessment of childhood traumatic events with all the well-known biases of that method (Herman and Harvey 1997). Lastly, we did not assess dissociation, which generally stems from a childhood history of complex traumatization, and contributes to the use of NSSI to prevent mental disintegration and disconnection (Levenkron 1998). To get a more nuanced picture of the characteristics and the development of NSSI, and especially, those of super self-injurers, future studies need to consider the specific interconnectedness of adverse childhood experiences, dissociation, and NSSI.

\section{CONCLUSIONS}

The findings of this study have important clinical implications. They add to our knowledge of inpatients who are super self-injurers who present a serious clinical challenge, associated with severe morbidity and greatly increased risk of mortality.

Our study suggests that the frequency of nonsuicidal self-injury in borderline inpatients can be regarded as an indicator of clinically relevant anamnestic data (namely, the severity, complexity and onset of childhood traumati- zation), and of the severity of current borderline psychopathology.

Furthermore, we have found that NSSI data, which is relatively easy to obtain, has a far-reaching potential to alert clinicians to the need to assess inpatients' underlying condition and probable childhood experiences.

We hope that our results will encourage clinicians to assess not just the presence or absence of NSSI, but also the lifetime frequency, onset and other characteristics of these behaviors, as we now know that they are likely to point to further important, clinically- relevant information.

\section{Acknowledgements:}

This research was realized in the frames of TÁMOP 4.2.4. A/1-11-1-2012-0001 "National Excellence Program - Elaborating and operating an inland student and researcher personal support system". The project was subsidized by the European Union and co-financed by the European Social Fund.

Conflict of interest: None to declare.

\section{Contribution of individual authors:}

Katalin Merza: design of the study, literature searches and analyses, statistical analyses, interpretation of data, first draft;

Gábor Papp: statistical analyses;

Judit Molnár: literature searches and analyses;

Ildikó Kuritárné Szabó: design of the study, literature searches and analyses, statistical analyses, interpretation of data, first draft.

\section{References}

1. American Psychiatric Association: Diagnostic and statistical manual of mental disorders: DSM-5. American Psychiatric Association, Washington, DC, 2013.

2. Bandelow B, Krause J, Wedekind D, Broocks A, Hajak G, Rüther E.: Early traumatic life events, parental attitudes, family history, and birth risk factors in patients with borderline personality disorder and healthy controls. Psychiat Res 2005; 134:169-79.

3. Bateman A \& Fonagy P: Impact of clinical severity on outcomes of metallization-based treatment for borderline personality disorder. Br J Psychiatry 2013; 203:221-27.

4. Bremner JD, Bolus $R \&$ Mayer EA: Psychometric properties of the Early Trauma Inventory-Self Report. $J$ Nerv Ment Dis 2007; 195:211-18.

5. Briere $J \&$ Gil E: Nonsuicidal self-injury in clinical and general population samples: prevalence, correlates, and functions. Am J Orthopsychiatry 1998; 68:609-20.

6. Brodsky BS, Cloitre $M \&$ Dulit RA: Relationship of dissociation and childhood abuse in borderline personality disorder. Am J Psychiatry 1995; 152:1788-92.

7. Brodsky BS, Malone KM, Ellis SP, Dulit RA, Mann JJ: Characteristics of borderline personality disorder associated with suicidal behavior. Am J Psychiatry 1997; 154:1715-19. 
8. Bunderla $T$ \& Kumperscak HG: Altered pain perception in self-injurious behavior and the association of psychological elements with pain perception measures: A systematic review. Psychiatr Danub 2015; 27:346-54.

9. Csorba J, Dinya E, Ferencz E, Páli E, Nagy E, Horváth Á, Vados M: A study of Hungarian adolescent outpatients suffering from self-injurious behavior. Psychiatr Danub 2010; 22: 39-45.

10. Csorba J, Szélesné Ferencz E, Steiner P, Németh Á: Önsértö magatartású középiskolás serdülök tüneti jellegzetességei. Psychiatr Hung 2005; 6:456-62.

11. Dubo E, Zanarini MC, Lewis RE, Williams BS: Relationship between lifetime self-destructiveness and pathological childhood experiences. In Zanarini MC (ed): Role of sexual abuse in the etiology of borderline personality disorder, 107-130. American Psychiatric Press, 1997.

12. Evren C, Kural $S$ \& Cakmak D: Clinical correlates of nonsuicidal self-injury is Turkish male substancedependent inpatients. Psychopathology 2006; 39:248-54.

13. Favazza AR: Nonsuicidal self-injury. In: Jacobs DG (ed). The Harvard Medical School guide to suicide assessment and intervention, 125-145. Jossey-Bass, 1999.

14. Fyer M: Suicide attempts in patients with borderline personality disorder. Am J Psychiatry 1988; 145:737-39.

15. Glenn CR \& Klonsky ED: Social context during nonsuicidal self-injury indicates suicide risk. Pers Individ Dif 2009; 46:25-9.

16. Golier JA, Yehuda R, Bierer LM, Mitropoulou V, New AS, Schmeidler J, Silverman JM, Siever LJ: The relationship of borderline personality disorder to posttraumatic stress disorder and traumatic events. Am J Psychiatry 2003; 160:2018-24.

17. Gunderson JG: Borderline personality disorder. American Psychiatric Press, Washington, DC, 1984.

18. Herman JL \& Harvey MR: Adult memories of childhood trauma: A naturalistic clinical study. J Trauma Stress 1997; 10:557-71.

19. Herpertz S: Self-injurious behavior. Psychopathological and nosological characteristics in subtypes of self-injurers. Acta Psychiat Scand 1995; 91:57-68.

20. Klonsky ED: The functions of deliberate self-injury: $A$ review of evidence. Clin Psychol Rev 2007; 27:226-39.

21. Klonsky ED: The functions of self-injury in young adults who cut themselves: Clarifying the evidence for affectregulation. Psychiatry Res 2009; 166:260-68.

22. Levenkron S: Cutting: Understanding and overcoming nonsuicidal self-injury. W.W. Norton, New York, 1998.

23. Linehan MM: Cognitive-behavioral treatment of borderline personality disorder. The Guilford Press, New York, 1993.

24. Martin $T$ \& Gattaz WF: Psychiatric aspects of male genital nonsuicidal self-injury. Psychopathology 1991; 24:170-78.

25. Matsumoto T, Azekawa T, Yamaguchi A, Asami T, Iseki E: Habitual nonsuicidal self-injury in Japan. Psychiatry Clin Neuropsych 2004; 58:191-98.

26. McLean LM \& Gallop R: Implications of childhood sexual abuse for adult borderline personality disorder and complex posttraumatic stress disorder. Am J Psychiatry 2003; 160:369-71.

27. Merza K, Papp G \& Kuritárné Szabó I: The role of childhood traumatization in the development of borderline personality disorder in Hungary. Eur J Psychiat 2015; 29:105-18.
28. Nijman HLI, Dautzenberg M, Merckelbach HLGJ, Jung P, Wessel I, Campo J: Self-mutilating behavior in psychiatric inpatients. Eur Psychiatry 1999; 14:4-10.

29. Nixon MK, Cloutier MA \& Aggrawal S: Affect regulation and addictive aspects of repetitive self-injury in hospitalized adolescents. Am Acad Child Adolesc Psychiatry 2002; 41:1333-41.

30. Nock MK, Joiner TE, Gordon KH, Lloyd-Richardson E, Prinstein MJ: Non-suicidal self-injury among adolescents: Diagnostic correlates and relation to suicide attempts. Psychiatry Res 2006; 144:65-72.

31. Paivio SC \& McCulloch CR: Alexithymia as a mediator between childhood trauma and self-injurious behaviors. Child Abuse Negl 2004; 28:339-54.

32. Paris JP \& Zweig-Frank H: Parameters of childhood sexual abuse in female patients. In: Zanarini MC, editor. Role of sexual abuse in the etiology of borderline personality disorder, 15-28. American Psychiatric Press, 1997.

33. Paul T, Schroeter K, Dahme B, Nutzinger DO: SelfInjurious behavior in women with eating disorders. Am J Psychiatry 2002; 159:408-11.

34. Romans SE, Martin JL, Anderson JC, Herbison GP, Mullen PE: Sexual abuse in childhood and deliberate selfharm. Am J Psychiatry 1995; 152:1336-42.

35. Russ MJ, Shearin EN, Clarkin JF, Harrison K, Hull JW: Subtypes of self-injurious patients with borderline personality disorder. Am J Psychiatry 1993; 150:1869-71.

36. Sabo AN: Etiological significance of associations between childhood trauma and borderline personality disorder: Conceptual and clinical implications. J Pers Disord 1997; 11:50-70.

37. Sansone R: Chronic suicidality and borderline personality disorder. J Pers Disord 2004; 18:215-25.

38. Sansone RA \& Levitt JL: Self-harm behaviors among those with eating disorders: An overview. Eat Disord 2002; 10:205-13.

39. Sansone RA\& Wiederman MW: Sex and age differences in symptoms in borderline personality symptomatology. Int J Psychiatry Clin Pract 2014; 18:145-49.

40. Sansone RA, Songer DA \& Miller KA: A naturalistic study of the relationship between self-harm behaviors and Axis I diagnostic groupings among inpatients. Int J Psychiatry Clin Pract 2007; 11:73-5.

41. Saxe GN, Van der Kolk BA, Berkowitz R, Chinman, G, Hall $K$, Leiberg $G$, et al.: Dissociative disorders in psychiatric inpatients. Am J Psychiat 1993; 150:1037-42.

42. Shearer SL, Peter CP \& Quaytman MS: Intent and lethality of suicide attempts among female borderline inpatients. Am J Psychiatry 1988; 145:1424-27.

43. Shearer SL: Phenomenology of self-injury among inpatient women with borderline personality disorder. $J$ Ment Dis 1994; 151:1324-28.

44. Silk K, Nigg JT, Westwn D, Lohr NE: Severity of childhood sexual abuse, borderline symptoms, and familiar environment. In: Zanarini MC, editor. Role of sexual abuse in the etiology of borderline personality disorder, 1131-164. American Psychiatric Press, 1997.

45. Stanley $B \&$ Brodsky BS: Suicidal and self-injurious behavior in borderline personality disorder: a selfregulation model. In: Gunderson JG, Hoffman PD, editors. Understanding and treating borderline personality disorder, 43-64. American Psychiatric Publishing Inc., 2005. 
46. Suyemoto KL: The functions of nonsuicidal self-injury. Clin Psychol Rev 1998; 18:531-54.

47. Swannell SV, Martin GE, Page A, Hasking P, St John MJ: Prevalence of nonsuicidal self-injury in nonclinical samples: systematic review, meta-analysis and metaregression. Suicide Life Threat Behav 2014; 44:273-303.

48. Szádóczky E, Rózsa $S$ \& Unoka Zs: Strukturált klinikai interjú a DSM-IV I. tengely zavarainak felmérésére. OS Hungary Tesztfejlesztő, Budapest, 2006.

49. Szádóczky E, Unoka Zs \& Rózsa S: Strukturált klinikai interjú a DSM-IV II. tengelyén található személyiségzavarok felmérésére. OS Hungary Tesztfejlesztö, Budapest, 2004.

50. van der Kolk BA \& Smyth N: Trauma Assessment Packet (CD-ROM). The Trauma Center at Justice Resource Institute, University of Buffalo School of Social Work, 2010.

51. van der Kolk BA, Perry JC \& Herman JL: Childhood origins of self-destructive behavior. Am J Psychiatry 1991; 148:1665-71.

52. Westen D, Ludolph P, Misle B, Ruffins S, Block J: Physical and sexual abuse in adolescent girls with borderline personality disorder. Am J Orthopsychiat 1990; 60:55-66.

53. Wingenfeld $K$, Schaffrath C, Rullkoetter N, Mensebach C, Schlosser N, Beblo T: Associations of childhood trauma, trauma in adulthood and previous-year stress with psychopathology in patients with major depression and borderline personality disorder. Child Abuse Negl 2011; 35:647-54.

54. Yates TM: The developmental psychopathology of selfinjurious behavior: Compensatory regulation in posttraumatic adaptation. Clin Psychol Rev 2004; 24:35-74.
55. Zanarini MC, Frankenburg FR, Reich DB, Frotzmaurice $G$, Weinberg I, Gunderson JG: The 10-year course of physically self-destructive acts reported by borderline patients and axis II comparison subjects. Acta Psychiat Scand 2008; 117:177-84.

56. Zanarini MC, Frankenburg FR, Ridolfi ME, Jager-Hyman $S$, Hennen J, Gunderson JG: Reported childhood onset of nonsuicidal self-injury among borderline patients. J Pers Disord 2006; 20:9-15.

57. Zanarini MC, Laudate CS, Frankenburg FR, Reich DB, Fitzmaurice G: Predictors of nonsuicidal self-injury in patients with borderline personality disorder: A 10-year follow-up study. J Psych Res 2011; 45:823-28.

58. Zanarini MC, Laudate CS, Frankenburg FR, Wedig MM, Fritzmaurice G: Reasons for nonsuicidal self-injury reported by borderline patients over 16 years of prospective follow-up. J Pers Disord 2013; 27:1-11.

59. Zanarini MC, Yong L, Frankenburg FR, Hennen J, Reich $D B$, Marino MF: Severity of reported childhood sexual abuse and its relationship to severity of borderline psychopathology and psychosocial impairment among borderline inpatients. J Nerv Ment Dis 2002; 190:381-87.

60. Zanarini MC: Childhood experiences associated with the development of borderline personality disorder. Psychiat Clin N Am 2000; 23:89-101.

61. Zlotnick C, Mattia JI \& Zimmerman M: Clinical correlates of nonsuicidal self-injury in a sample of general psychiatric patients. J Nerv Ment Dis 1999; 187:296-301.

62. Zweig-Frank $H \&$ Paris J: Relationship of childhood sexual abuse to dissociation and nonsuicidal self-injury in female patients. In: Zanarini MC (ed): Role of sexual abuse in the etiology of borderline personality disorder, 93-106. American Psychiatric Press, 1997.

Correspondence:

Katalin Merza, psychologist, PhD student

University of Debrecen, Faculty of Public Health, Institute of Behavioral Sciences

Nagyerdei krt. 98. P.O. Box: 45, H-4032 Debrecen, Hungary

E-mail:merza.katalin@sph.unideb.hu 